\title{
ACHIEVING MAXIMUM SFN SIZE FOR A DVB-T2 TRANSMISSION SYSTEM
}

\section{Loreta Andoni ${ }^{1}$}

\begin{abstract}
The GE-06 Agreement "On planning the terrestrial digital broadcasting services in parts of Region 1 and 3, in the frequency bands of 174-230 MHz and 470-862 MHz" has been based in the DVB-T system of transmission. Most of the signatory countries of this agreement use or are going to use the most advanced digital terrestrial technology such as DVBT2. One of the main advantages of DVB-T2 comparing with DVB-T is an increased size of SFN networks, which is closely related with guard interval or inter-transmitters distances. To achieve the maximum size of DVB-T2 SFNs, it is important to find optimal parameters of DVB-T2 networks. But even though the GE-06 Plan gives opportunities to implement DVB-T2 there are some limitations on using all its benefits. One of these limitations is the availability to increase the distance between transmitters because changes in the location of any transmitter require long and intensive coordination with neighboring countries. The aim of this paper is to investigate the optimal DVB-T2 networks configuration for two existing SFN networks in Albania with the purpose to achieve maximum SFN size without adding transmitters or changing the location of existing transmitters.
\end{abstract}

UDC Classification: 654.1; DOI: http://dx.doi.org/10.12955/cbup.v6.1284

Keywords: DVB-T2, SFN size, guard interval, transmitters distance, network parameters

\section{Introduction}

Albania as part of Region 1 of ITU is one of the countries that signed the GE-06 Agreement "On planning the terrestrial digital broadcasting services in parts of Region 1 and 3, in the frequency bands of $174-230 \mathrm{MHz}$ and $470-862 \mathrm{MHz}$ ". A large number of coordinating, bilateral, and multilateral meetings between neighbour countries were organized to achieve the GE-06 Agreement and finalise the frequency plan attached to this agreement. The final aim of the agreements was equal use, not a discriminating use, of the limited resources of the frequency spectrum in order for digital broadcasting to meet the requirement of each country, both in quantity and quality, as well as to not cause damaging interferences in the broadcasting of the respective state. The Digital Frequency Plan approved by the GE-06 Agreement provides for Albania 7 national digital networks with DVB-T in the UHF band, 7 local coverages with DVB-T in the UHF band for a sub-allotment in the capital city, a number of local coverages in some areas of the country, and coverages in the VHF band. The National Frequency Plan envisions a division of the territory of Albania into 11 allotments each of them covered by a single frequency network (SFN).

The big challenge nowadays is the considerable reduction of digital broadcasting capacities due to the need to release the Digital Dividend bands, which will be used by advanced technologies, including mobile communications.

Given that all terrestrial digital TV networks in Albania are based on DVB-T2 technology, meanwhile respecting the GE-06 plan which is DVB-T based, the aim of this paper is to analyse the optimal DVB-T2 networks configurations which provides a larger size for the existing SFNs. Taking into account that changes in the GE-06 plan require much coordination with neighbour countries, the system parameters that are set in this plan such as the effective antenna height, effectively radiated power (ERP) and location of the transmitters will be considered as fixed and unchanged. It's also considered important to provide a data rate which is not lower than the one offered by the existing networks.

In regards to the length of the guard interval further investigations are going to be performed in order to evaluate the opportunities of merging two SFNs in one single large SFN achieving as result the release of one frequency.

\section{Network Parameters}

In evaluating the network configurations with the purpose to find the ones that best fulfill the specific requirements in the specific service areas, a number of factors such as the existing available infrastructure, the population distribution, terrain databases, buildings and other clutter layers should be taken in consideration ( $\mathrm{Li}$ et al., 2015). The existing infrastructure of the service areas which is the object of the analyses is covered by two SFNs with the network configuration: $8 \mathrm{MHz}$ bandwidth, 64

\footnotetext{
${ }^{1}$ Polytechnic University of Tirana, Albania, andoniloreta@yahoo.com
} 


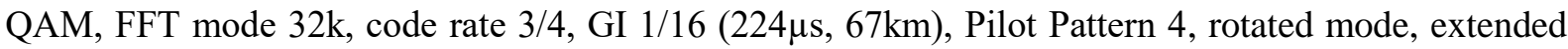
mode, data rate $31.2 \mathrm{Mbit} / \mathrm{s}$.

\section{SFN size and throughput}

The limitations for achieving a maximum inter-transmission distance and the maximum size of an SFN is due to self-interference. This is the main challenge of a network using a single frequency. The longest guard interval reached in a DVB-T system is $224 \mu$ s while in a DVB-T2 system is $448 \mu \mathrm{s}$. By using a system bandwidth of $8 \mathrm{MHz}, \mathrm{DVB}-\mathrm{T}$ allows a maximum transmitter separation distance of $67.2 \mathrm{~km}$ while DVB-T2 allows for a distance of $159.6 \mathrm{~km}$ (Gimenez et al, 2015).

Studies have shown that if the $\mathrm{C} / \mathrm{N}$ requirements are close to $20 \mathrm{~dB}$ and the bitrate over $30 \mathrm{Mbps}$, the SFN network can reach 360 x $360 \mathrm{~km}$ (giving $39.2 \mathrm{Mbps}$ ) or even 720 x $720 \mathrm{~km}$ (delivering 37.5 Mbps). The configuration for achieving large and very large SFN and their corresponding maximum data rates are shown in Table 1 (EBU TR 029, 2014).

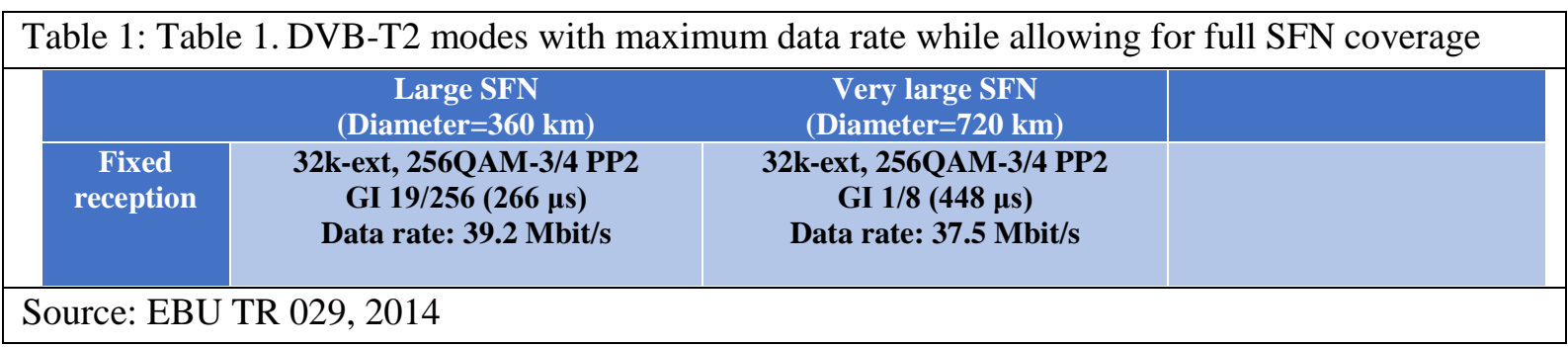

Increasing the SFN size enables a more efficiently use of the scarce resource of spectrum. Nevertheless, large SFNs require an increased guard interval that reduces the capacity and as well as limits the possibilities to provide regional services.

Finding the right configuration to maximize the size of an SFN is very difficult due to the large number of parameters of the system. Comparing DVB-T2 with DVB-T offers big advantages of using additional FFT sizes of $1 \mathrm{k}, 4 \mathrm{k}, 16 \mathrm{k}$ and 32k, as well as additional GI values: 1/128, 19/256 and 19/128 (Beutler, 2008).

A trade-off between the SFN size and signal throughput is needed to be found. As the GI increases, the signal throughput decreases, as it's illustrates in Figure 1.

\begin{tabular}{|l|l|}
\hline Figure 1: GI-throughput connection \\
\hline TXs distance in DVB-T2 SFN \\
\end{tabular}

Source: Author

\section{Modulation-Code rate}

A modulation scheme together with a code rate are the most predominant system parameters influencing $\mathrm{C} / \mathrm{N}$ and bitrate. A trade-off between capacity and robustness needs to be found when the transmission mode has to be selected. The choice of an SFN operation mode would be based on the length of the guard interval according to the physical size of the SFN. The GI fraction is connected with the FFT size which relate to the reception scenario: fixed rooftop, portable or mobile reception. In the case of fixed rooftop, the reception that is recommended to be used is $32 \mathrm{k}$ or $16 \mathrm{k}$ FFT, given that a 
larger FFT size would reduce the GI fraction and increase the capacity (Bigeni, 2012). Figure 2 shows the data rate and $\mathrm{C} / \mathrm{N}$ values for each modulation-coding scheme.

\begin{tabular}{|c|c|c|c|c|}
\hline \multicolumn{5}{|c|}{ Figure 2: Data rates and C/N values in DVB-T2 } \\
\hline Coderate & QPSK & 16 QAM & 64 QAM & 256 QAM \\
\hline $1 / 2$ & $\begin{array}{l}7.5 \mathrm{Mbit} / \mathrm{s} \\
0.8 \mathrm{~dB} \\
\end{array}$ & $\begin{array}{l}15.0 \mathrm{Mbit} / \mathrm{s} \\
5.7 \mathrm{~dB}\end{array}$ & $\begin{array}{l}22.5 \mathrm{Mbit} / \mathrm{s} \\
9.6 \mathrm{~dB}\end{array}$ & $\begin{array}{l}30.1 \mathrm{Mbit} / \mathrm{s} \\
12.8 \mathrm{~dB}\end{array}$ \\
\hline $3 / 5$ & $\begin{array}{l}9.0 \mathrm{Mbit} / \mathrm{s} \\
2.1 \mathrm{~dB}\end{array}$ & $\begin{array}{l}18.1 \mathrm{Mbit} / \mathrm{s} \\
7.4 \mathrm{~dB}\end{array}$ & $\begin{array}{l}27.1 \mathrm{Mbit} / \mathrm{s} \\
11.7 \mathrm{~dB}\end{array}$ & $\begin{array}{l}36.2 \mathrm{Mbit} / \mathrm{s} \\
15.6 \mathrm{~dB}\end{array}$ \\
\hline $2 / 3$ & $\begin{array}{l}10.0 \mathrm{Mbit} / \mathrm{s} \\
2.9 \mathrm{~dB}\end{array}$ & $\begin{array}{l}20.1 \mathrm{Mbit} / \mathrm{s} \\
8.6 \mathrm{~dB}\end{array}$ & $\begin{array}{l}30.1 \mathrm{Mbit} / \mathrm{s} \\
13.2 \mathrm{~dB}\end{array}$ & $\begin{array}{l}40.2 \mathrm{Mbit} / \mathrm{s} \\
17.5 \mathrm{~dB}\end{array}$ \\
\hline $3 / 4$ & $\begin{array}{l}11.3 \mathrm{Mbit} / \mathrm{s} \\
3.9 \mathrm{~dB}\end{array}$ & $\begin{array}{l}22.6 \mathrm{Mbit} / \mathrm{s} \\
9.8 \mathrm{~dB}\end{array}$ & $\begin{array}{l}33.9 \mathrm{Mbit} / \mathrm{s} \\
14.9 \mathrm{~dB}\end{array}$ & $\begin{array}{l}45.2 \mathrm{Mbit} / \mathrm{s} \\
17.5 \mathrm{~dB}\end{array}$ \\
\hline $4 / 5$ & $\begin{array}{l}12.0 \mathrm{Mbit} / \mathrm{s} \\
4.5 \mathrm{~dB}\end{array}$ & $\begin{array}{l}24.1 \mathrm{Mbit} / \mathrm{s} \\
10.6 \mathrm{~dB}\end{array}$ & $\begin{array}{l}36.1 \mathrm{Mbit} / \mathrm{s} \\
15.9 \mathrm{~dB}\end{array}$ & $\begin{array}{l}48.3 \mathrm{Mbit} / \mathrm{s} \\
21.1 \mathrm{~dB}\end{array}$ \\
\hline $5 / 6$ & $\begin{array}{l}12.5 \mathrm{Mbit} / \mathrm{s} \\
5.0 \mathrm{~dB}\end{array}$ & $\begin{array}{l}25.2 \mathrm{Mbit} / \mathrm{s} \\
11.2 \mathrm{~dB}\end{array}$ & $\begin{array}{l}37.7 \mathrm{Mbit} / \mathrm{s} \\
16.6 \mathrm{~dB}\end{array}$ & $\begin{array}{l}50.3 \mathrm{Mbit} / \mathrm{s} \\
21.8 \mathrm{~dB}\end{array}$ \\
\hline
\end{tabular}

In selecting the modulation scheme, the required capacity .needs to be taken into account. Higher order modulation schemes offer more capacity. The modulation scheme also has a large impact upon the robustness of the system which needs to be carefully investigated.

In DVB-T2, the additional 256-QAM modulation scheme is available, with new error protection techniques.

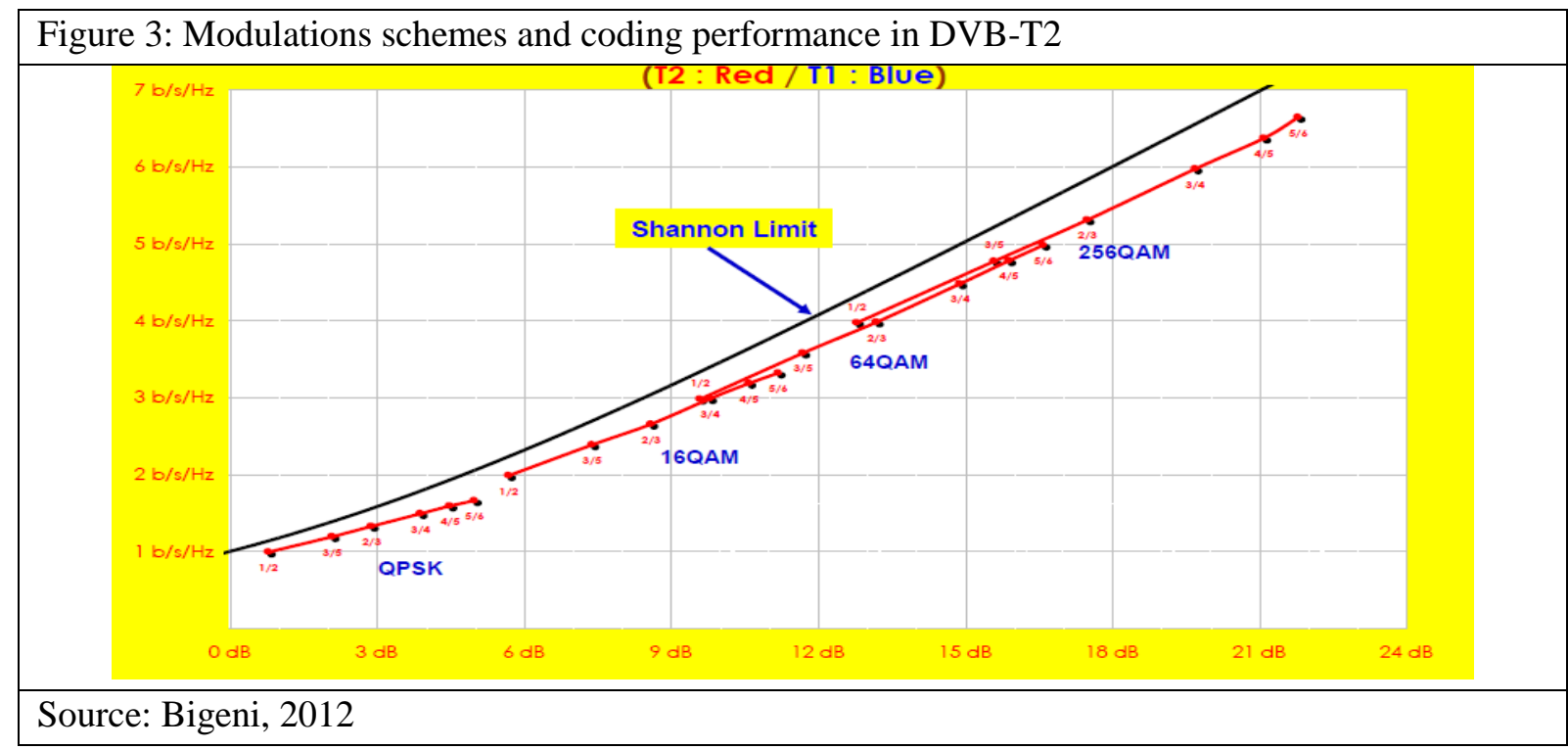

However, the performance of the 256-QAM in DVB-T2 differs from the theoretical models and the performance is degraded when using this new feature. DVB-T2 64 QAM behaves better than 256 QAM for a similar bit rate. For Gaussian and Rician channels it is better to select 64 QAM, with medium or low protection $(2 / 3,3 / 4,4 / 5$ and $5 / 6)$ to realize higher performance than the highly protected 256 QAM (1/2 and 3/5) (Eizmendi et al., 2013), because similar bitrates are provided with lower $\mathrm{C} / \mathrm{N}$ requirements as is illustrated in Figure 3.

\section{Carrier-to-Noise Ratio (C/N)}

The $\mathrm{C} / \mathrm{N}$ level determines the robustness of transmission systems with regards to noise and interference. If the size of the SFN increases the total coverage is guaranteed only if the $\mathrm{C} / \mathrm{N}$ and consequently the throughput decrease. If the $\mathrm{C} / \mathrm{N}$ requirement is too high, some of the locations in the 
coverage area cannot reach the minimum QoS criterion and the percentage of coverage locations of the service area decreases. Table 2 illustrate the connection between bitrate and $\mathrm{C} / \mathrm{N}$ range.

\begin{tabular}{|l|l|l|}
\hline Table 2: $\mathrm{C} / \mathrm{N}$ and bitrate ranges & & \\
\hline \multicolumn{1}{|c|}{$\begin{array}{l}\text { Reception Mode } \\
\text { Fixed }\end{array}$} & Bitrate Range [Mbit/s] & C/N Range [dB] \\
& $18.3=<$ Rate $<=36.9$ & $13.3<=\mathrm{C} / \mathrm{N}<=23.2$ \\
\hline Source: Sato et al., 2015 & & \\
\hline
\end{tabular}

The determination of the $\mathrm{C} / \mathrm{N}$ is of fundamental importance to network planning. Different combination between modulation schemes, code rates and pilot patterns for are required for different $\mathrm{C} / \mathrm{N}$ receiver thresholds which affect the SFN coverage performance.

Table 3 provides a range of representative DVB-T2 transmission modes. The Rician channel is applied for fixed reception to calculate the required C/N (Sato et al., 2015).

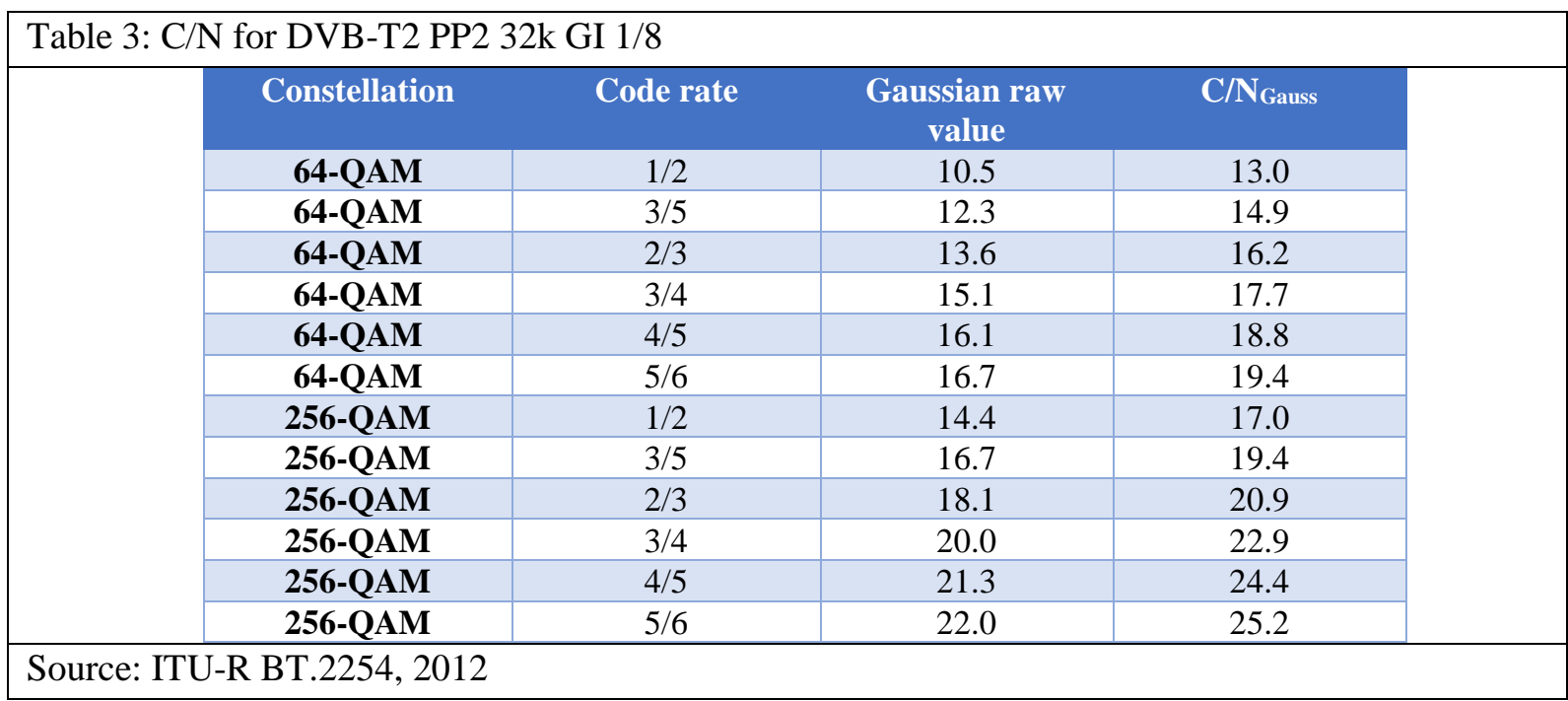

In order to determine the appropriate $\mathrm{C} / \mathrm{N}$ to be used for the fixed reception of digital television for the tradeoff between capacity, coverage and cost need to be set. After the DVB-T2 modulation mode is chosen, the simulated $\mathrm{C} / \mathrm{N}$ for a Gaussian channel (C/N Gauss-raw) can be found and used as the base value for the proposed method (ITU-R BT.2254-3, 2017).

\begin{tabular}{|c|c|c|c|c|c|c|c|}
\hline FFT size & & & & Guard Interval & & & \\
\hline & $1 / 128$ & $1 / 32$ & $1 / 16$ & $19 / 256$ & $1 / 8$ & $19 / 128$ & $1 / 4$ \\
\hline $32 \mathrm{k}$ & PP7 & $\begin{array}{l}\text { PP4 } \\
\text { PP6 }\end{array}$ & $\begin{array}{l}\text { PP2 } \\
\text { PP8 } \\
\text { PP4 }\end{array}$ & $\begin{array}{l}\text { PP2 } \\
\text { PP8 } \\
\text { PP4 }\end{array}$ & $\begin{array}{l}\text { PP2 } \\
\text { PP8 }\end{array}$ & $\begin{array}{l}\text { PP2 } \\
\text { PP8 }\end{array}$ & $\mathrm{n} / \mathrm{a}$ \\
\hline 16k & PP7 & $\begin{array}{l}\text { PP7 } \\
\text { PP4 } \\
\text { PP6 }\end{array}$ & $\begin{array}{l}\text { PP2 } \\
\text { PP8 } \\
\text { PP4 } \\
\text { PP5 }\end{array}$ & $\begin{array}{l}\text { PP2 } \\
\text { PP8 } \\
\text { PP4 } \\
\text { PP5 }\end{array}$ & $\begin{array}{l}\text { PP2 } \\
\text { PP3 } \\
\text { PP8 }\end{array}$ & $\begin{array}{l}\text { PP2 } \\
\text { PP3 } \\
\text { PP8 }\end{array}$ & $\begin{array}{l}\text { PP1 } \\
\text { PP8 }\end{array}$ \\
\hline $8 \mathbf{k}$ & PP7 & $\begin{array}{l}\text { PP7 } \\
\text { PP4 }\end{array}$ & $\begin{array}{l}\text { PP8 } \\
\text { PP4 } \\
\text { PP5 }\end{array}$ & $\begin{array}{l}\text { PP8 } \\
\text { PP4 } \\
\text { PP5 }\end{array}$ & $\begin{array}{l}\text { PP2 } \\
\text { PP3 } \\
\text { PP8 }\end{array}$ & $\begin{array}{l}\text { PP2 } \\
\text { PP3 } \\
\text { PP8 }\end{array}$ & PP1 PP8 \\
\hline $4 \mathrm{k}, 2 \mathrm{k}$ & $\mathrm{n} / \mathrm{a}$ & $\begin{array}{l}\text { PP7 } \\
\text { PP4 }\end{array}$ & $\begin{array}{l}\text { PP4 } \\
\text { PP5 }\end{array}$ & $\mathrm{n} / \mathrm{a}$ & $\begin{array}{l}\text { PP2 } \\
\text { PP3 }\end{array}$ & $\mathrm{n} / \mathrm{a}$ & PP1 \\
\hline $1 \mathrm{k}$ & $\mathrm{n} / \mathrm{a}$ & $\mathrm{n} / \mathrm{a}$ & $\begin{array}{l}\text { PP4 } \\
\text { PP5 }\end{array}$ & $\mathrm{n} / \mathrm{a}$ & $\begin{array}{l}\text { PP2 } \\
\text { PP3 }\end{array}$ & $\mathrm{n} / \mathrm{a}$ & PP1 \\
\hline
\end{tabular}

\section{Pilot Pattern}

Pilots are carriers that serve to estimate pilot tones which are used to estimate the channel. DVB-T2 uses eight different scattered pilots to make measurements of the channel and to estimate the channel response for every OFDM cell so that distortions in the received signal may be corrected. If the pilot 
density is sufficiently high they can follow channel fluctuations as a function of both frequency and time. However, only a subset of pilot patterns is permitted for each FFT size and GI combination. In large SFN networks where a 1/8 or greater guard interval is required, only patterns 1,2 or 3 would be available (Table 4).

Theoretically the best operation is expected in PP2 and the worst-case in PP8 (ITU-R BT.2254-03, 2017). Each of the patterns are more suited to their particular channel types and this gives them more flexibility during network planning to match the transmission mode and the pilot pattern for each intended transmission channel or payload requirement. The structure of the scattered pilot pattern PP2 and PP4 are shown in Figure 4.

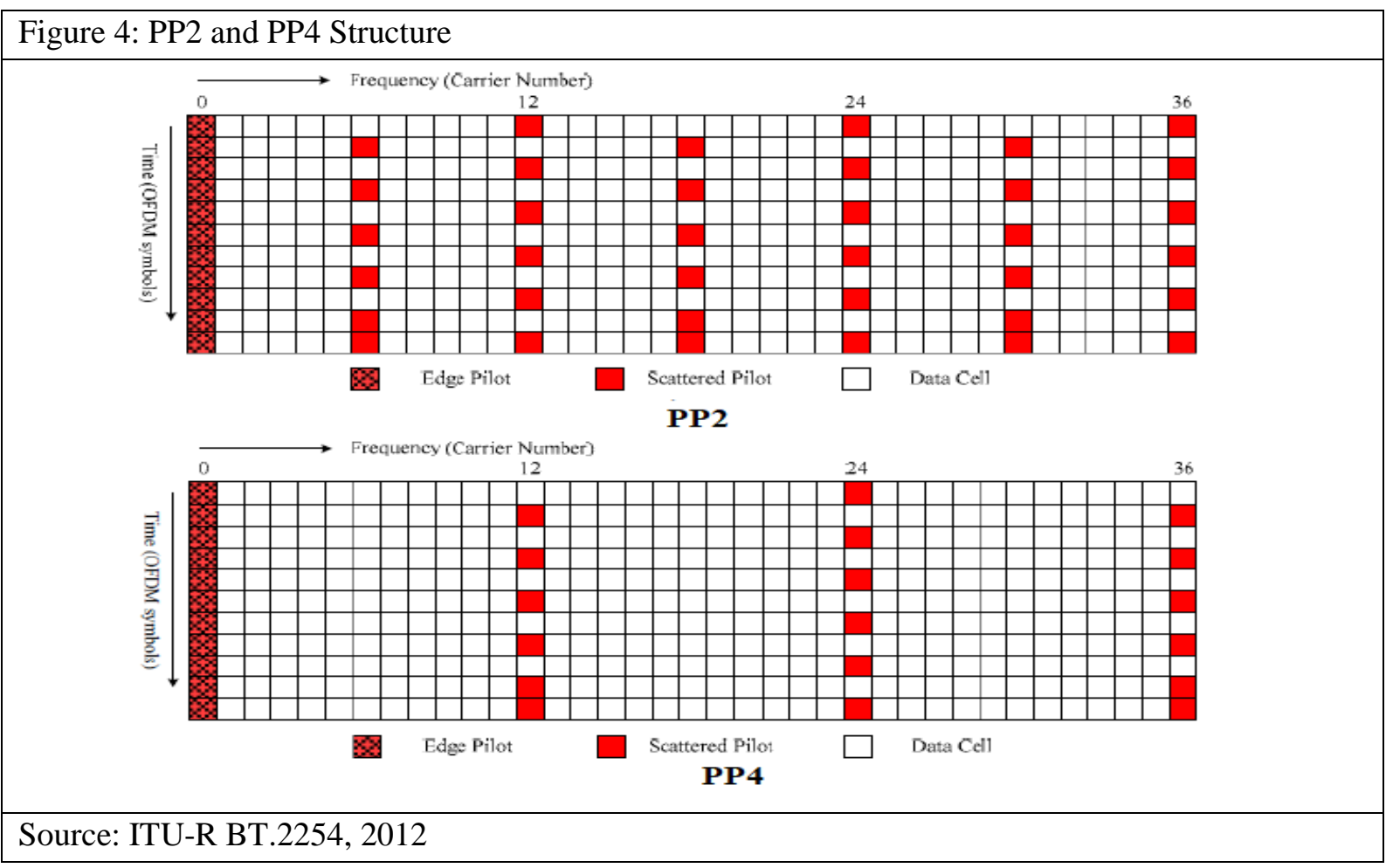

\section{FFT size and Guard Interval}

In DVB-T2 systems there are six different FFT sizes which are named transmission modes: $1 \mathrm{~K}, 2 \mathrm{~K}$, $4 \mathrm{~K}, 8 \mathrm{~K}, 16 \mathrm{~K}$ and $32 \mathrm{~K}$. A DVB-T2 transmitted signal is organized into frames. A carrier in DVB-T2 contains the useful part and the guard interval. The FFT size must be greater than the number of modulated carriers in order to make the analogue reconstruction filters realizable. Furthermore, the number of modulated carriers in a given bandwidth determines the inter-carrier spacing. The distance of an SFN transmitter increases as the FFT size increases.

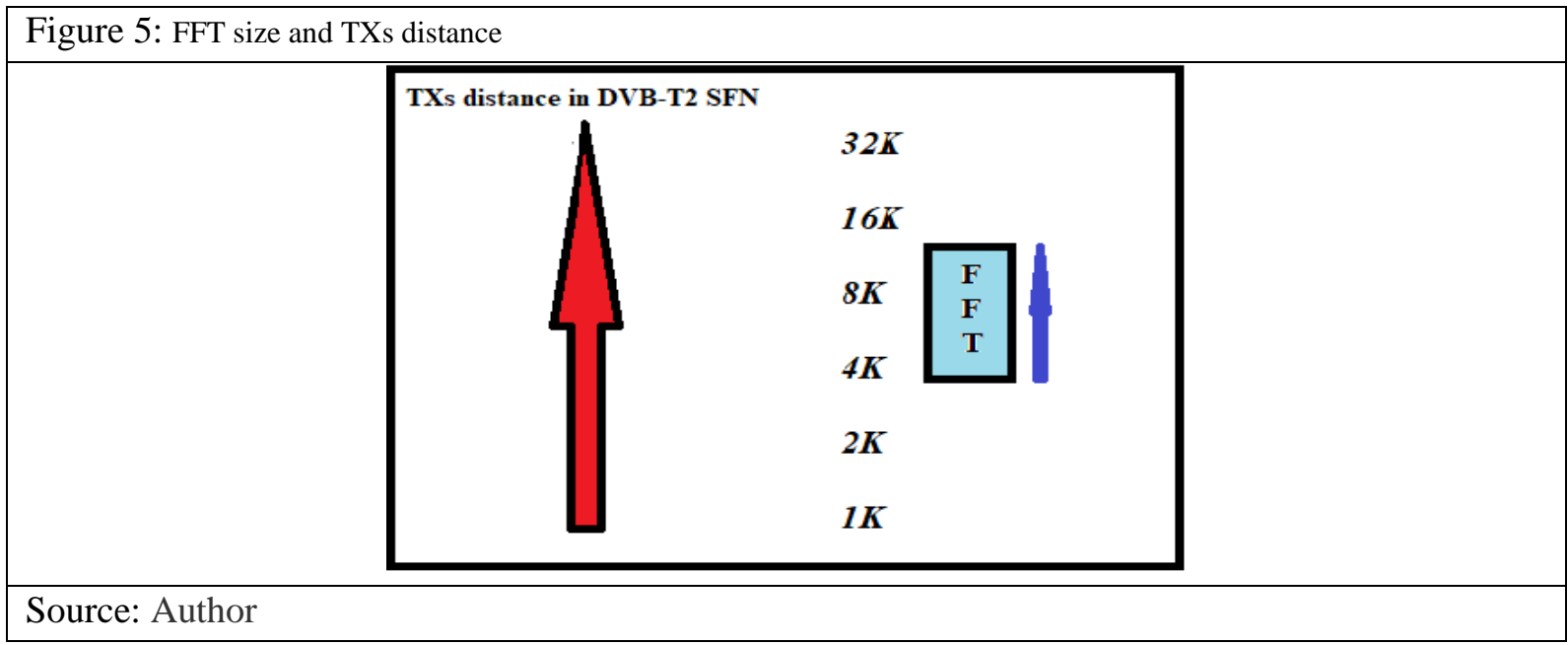


In DVB-T2, 16K and 32K FFT sizes makes it possible to have much longer guard interval which makes it possible to build larger SFN networks. For a high-bit-rate service and fixed rooftop antennas, the $32 \mathrm{k}$ mode is recommended. Increased FFT size will give a greater delay tolerance for the same fractional guard interval, allowing a larger SFN to be constructed (ITU-R BT.2254, 2012). A larger FFT size entails a longer symbol duration, which means that the guard interval fraction is smaller for a given guard interval duration in time. Additionally, the larger FFT sizes have a greater vulnerability to fast time-varying channels, i.e. have lower Doppler performance (ITU-R BT.2254, 2012).

\section{Conclusion}

The second generation of digital terrestrial transmission "DVB-T2" is an extremely flexible and functional system and offers varies opportunities to cover a certain area using as little frequencies as possible. A number of configuration options allows the system to maximize the robustness, capacity and SFN size according to the intended reception scenarios. Finding the optimal configuration is a very difficult process due to the large number of parameters. In this paper an effort is made to find the optimal system configuration which allow for an increased SFN size while maintaining a similar throughput within the existing network.

The relation between the operating mode, throughput, $\mathrm{C} / \mathrm{N}$, guard interval and SFN size have been analyzed. The analysis was been carried out using theoretical hypothesis, conclusions from other studies analyzing similar cases, and the existing network architecture.

Based on the analysis made in this paper, in order to increase the size of the existing SFNs taken as a reference, it is recommended to use the DVB-T2 variants 64-QAM, code rate $3 / 4$, 32k FFT, GI 1/8 and Pilot Pattern PP2. However other investigations are needed in order to perform an overall simulation of all transmission sites. Finally, it is also important to find the compromise between increased SFN size and the data rate.

\section{References}

Beutler, R. (2008). Digital Terrestrial Broadcasting Systems. Lecture Notes in Electrical Engineering Digital Terrestrial Broadcasting Networks, 1-33.

Bigeni, J. (2012). DVB-T/T2 Fundamentals - Technical University of Košice. (n.d.). Caiwei, L., Sato, T., Pablo, A., Roland, B., Xiaolin, Z., Javier, M., . . Zhan, Z. (2014). Optimal DVB-T2 network planning using theoretical SFNs. 2014 IEEE International Symposium on Broadband Multimedia Systems and Broadcasting.

Channel Coding and Modulation for Digital Television. (n.d.). Fundamentals of Digital Television Transmission, 43-66. doi:10.1002/0471213764.ch3

EN 300744 - V1.1.2 - Digital Video Broadcasting (DVB ... (n.d.).

E. (Ed.). (n.d.). Frequency and network planning aspects of DVB-T2.

Eizmendi, I., Prieto, G., Berjon-Eriz, G., Landa, I., \& Velez, M. (2013). Empirical DVB-T2 Thresholds for Fixed Reception. IEEE Transactions on Broadcasting, 59(2), 306-316.

Eizmendi, I., Velez, M., Gomez-Barquero, D., Morgade, J., Baena-Lecuyer, V., Slimani, M., \& Zoellner, J. (2014). DVB-T2: The Second Generation of Terrestrial Digital Video Broadcasting System. IEEE Transactions on Broadcasting, 60(2), 258271.

Frequency and network planning aspects of DVB-T2. (n.d.). https://www.itu.int/dms_pub/itu-r/opb/rep/R-REP-BT.2254-32017-PDF-E.pdf\&p=DevEx,5079.1

Gimenez, J. J., Stare, E., Bergsmark, S., \& Gomez-Barquero, D. (2015). Advanced Network Planning for Time Frequency Slicing (TFS) Toward Enhanced Efficiency of the Next-Generation Terrestrial Broadcast Networks. IEEE Transactions on Broadcasting, 61(2), 309-322

Lanza, M., Gutierrez, A. L., Perez, J. R., Morgade, J., Domingo, M., Valle, L., . . Basterrechea, J. (2014). Coverage Optimization and Power Reduction in SFN Using Simulated Annealing. IEEE Transactions on Broadcasting, 60(3), 474-485.

Li, C., Telemi, S., Zhang, X., Brugger, R., Angulo, I., \& Angueira, P. (2015). Planning Large Single Frequency Networks for DVB-T2. IEEE Transactions on Broadcasting, 61(3), 376-387. doi:10.1109/tbc.2015.2419179

Morgade, J., Angueira, P., Arrinda, A., Pfeffer, R., Steinmann, V., Frank, J., \& Brugger, R. (2014). SFN-SISO and SFNMISO Gain Performance Analysis for DVB-T2 Network Planning. IEEE Transactions on Broadcasting, 60(2), 272-286.

ITU, "GE06 Agreement: Final Acts of the Regional Radiocommunication Conference for planning of the digital terrestrial broadcasting service in parts of Regions 1 and 3, in the frequency bands 174-230 MHz and 470-862 MHz (RRC-06), ITU, Geneva, 2006ETSI,

Sato, T., Roland, B., Ivan, P., \& Pablo, A. (2015). A comparison between theoretical and practical planning approaches for DVB-T2 single frequency networks. 2015 IEEE International Symposium on Broadband Multimedia Systems and Broadcasting. 